\title{
Inoperable aortic stenosis in the elderly: benefit from percutaneous transluminal valvuloplasty
}

\author{
GRAHAM JACKSON, STEPHEN THOMAS, MARK MONAGHAN, ANDREW FORSYTH, \\ DAVID JEWITT
}

\begin{abstract}
Eight patients with severe symptomatic calcific aortic stenosis were considered to be unsuitable for valve replacement. Four were admitted with pulmonary oedema and three in cardiogenic shock and one had angina at rest. With the use of echocardiographic and radiographic guidance percutaneous transluminal aortic valvuloplasty was carried out. Aortic gradients were reduced by an average of $40 \%$.

All four patients who presented with cardiac failure improved immediately and remained well six months later. The patient with angina was symptom free at nine months. Two of the three patients who presented in cardiogenic shock improved immediately and were well nine and three months later. The other patient died four hours after the procedure. Doppler echocardiographic studies showed a slight initial increase in aortic incompetence, but this did not worsen and valvar gradients remained improved three and six months later.

Percutaneous valvuloplasty of the aortic valve is an effective therapeutic option in patients with severe calcific aortic stenosis who are unfit for surgery. Its role as an alternative to surgery has not been considered and should be investigated in a controlled clinical trial.
\end{abstract}

\section{Introduction}

Without surgical intervention symptomatic aortic stenosis has a poor prognosis with a life expectancy of only two to four years: ${ }^{\prime}$ Aortic valve replacement is a highly effective treatment with an

Cardiac Department, King's College Hospital, London SE5 9RS

GRAHAM JACKSON, FRCP, consultant cardiologist

STEPHEN THOMAS, SRN, charge nurse

MARK MONAGHAN, MSC, chief technician

ANDREW FORSYTH, FRCS, consultant cardiac surgeon

DAVID JEWITT, FRCP, consultant cardiologist

Correspondence to: Dr Jackson. operative mortality of 7-10\% and good symptomatic and prognostic results. ${ }^{2}$ Not all patients, however, are acceptable surgical candidates. Some may have other life shortening illnesses-for example, cancer or renal disease-be limited by severe respiratory disease, or simply be considered to be too old and infirm to benefit. Others may present with such severe heart failure or cardiogenic shock that time is needed to stabilise the haemodynamics to reduce the operative risk.

Percutaneous transluminal balloon dilatation of the aortic valve in elderly patients was first reported by Cribier $e t$ al, who documented symptomatic and haemodynamic benefit without complications in three patients. ${ }^{3}$ We thought it might be possible to use percutaneous transluminal aortic valvuloplasty in patients presenting with severe symptomatic aortic stenosis who were not considered to be suitable candidates for surgery. In order to assess the safety of the procedure we conducted intraoperative studies and postmortem studies before performing the procedure in eight patients. We report here on our results and outline some of the technical aspects of the procedure.

\section{Patients and methods \\ INTRAOPERATIVE AND POSTMORTEM STUDIES}

Ten patients undergoing aortic valve replacement were evaluated after cross clamping of the aorta. Olbert or Medi-Tech balloon catheters 10-16 $\mathrm{mm}$ in diameter were advanced retrogradely through the valve and inflated for one minute on two occasions. The valve was inspected immediately after the procedure, and a video recording of the dilatation was analysed later.

Five postmortem specimens were evaluated in the laboratory. In two cases we studied the intact heart after complete removal, and in three the excised valve was dilated. Dilatations were made with Olbert and MediTech balloon catheters for one minute at 4-9 atmospheres using 10-16 mm balloons. The valves were inspected after each dilatation (fig 1).

\section{PATIENT STUDIES}

After detailed, informed, written consent had been obtained eight patients, aged 68-81, underwent percutaneous transluminal aortic valvuloplasty. All were considered to be poor surgical candidates at presentation 

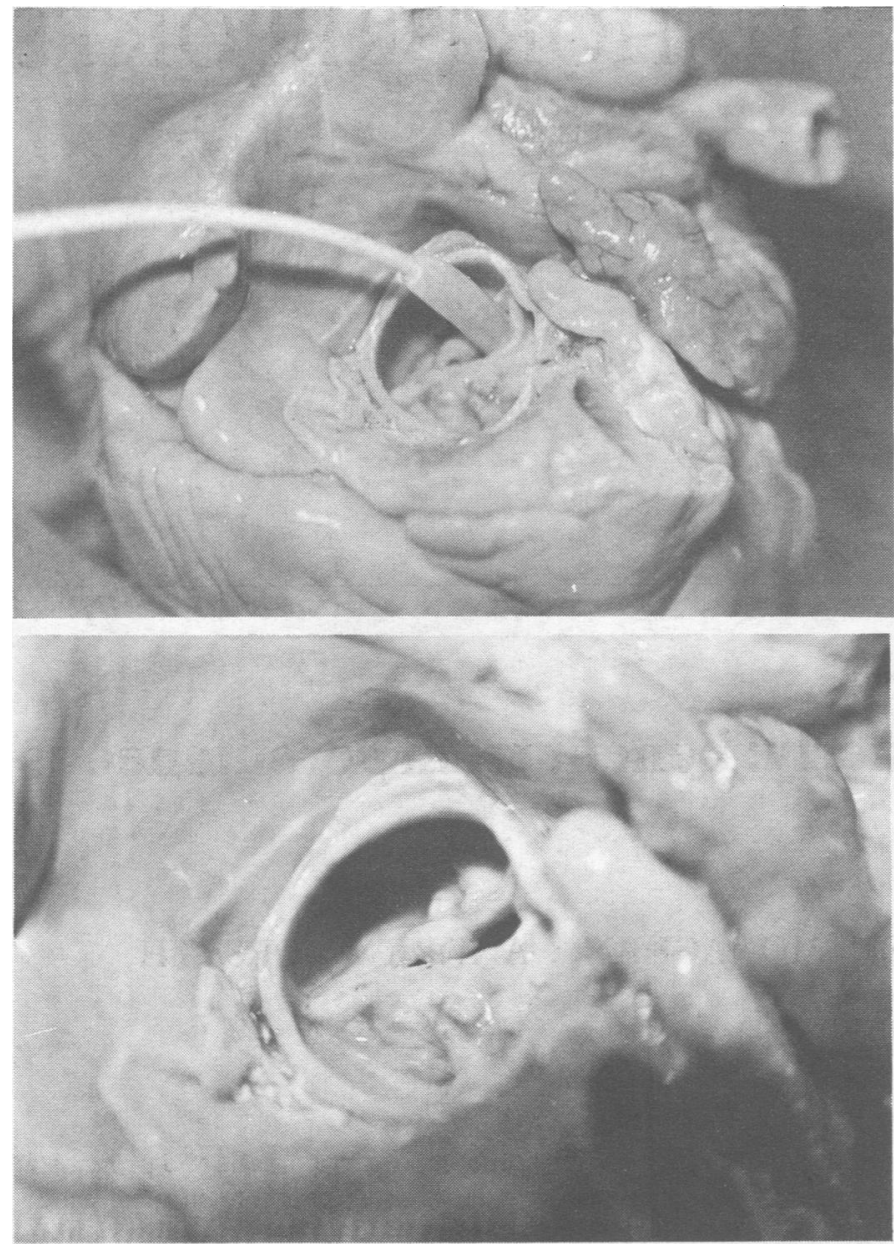

FIG 1-Above: balloon in situ inflating a bicuspid. aortic valve. Below: postvalvuloplasty cusp separation.

Details of eight patients who underwent percutaneous transluminal aortic valvuloplasty

\begin{tabular}{|c|c|c|c|}
\hline $\begin{array}{c}\text { Case } \\
\text { No }\end{array}$ & Age & Condition at presentation & Reason for unsuitability for surgery \\
\hline $\begin{array}{l}1 \\
2 \\
3 \\
4 \\
5 \\
6 \\
7 \\
8\end{array}$ & $\begin{array}{l}70 \\
81 \\
73 \\
73 \\
76 \\
77 \\
73 \\
68\end{array}$ & $\begin{array}{l}\text { Shock, pulmonary oedema } \\
\text { Angina } \\
\text { Shock, pulmonary oedema } \\
\text { Pulmonary oedema } \\
\text { Pulmonary oedema } \\
\text { Pulmonary oedema } \\
\text { Pulmonary oedema } \\
\text { Shock, pulmonary oedema }\end{array}$ & $\begin{array}{l}\text { Severe rheumatoid arthritis, lung disease } \\
\text { Infirm } \\
\text { Cancer, chronic lung disease } \\
\text { Infirm, mitral valve disease, lung disease } \\
\text { Chronic lung disease } \\
\text { Infirm } \\
\text { Cancer of lung (asbestosis) } \\
\text { Haemodynamic state }\end{array}$ \\
\hline
\end{tabular}

(table I). Three patients presented in cardiogenic shock, four had pulmonary oedema, and one suffered angina at rest. All patients initially received conventional treatment to stabilise their condition. One shocked patient required ventilation, diuretics, and inotropic support for three days, and her aortic valve was dilated when she was still dependent on inotropic drugs but not receiving the ventilation. The two others had their valves dilated while still receiving inotropic support with aortic systolic pressures below $100 \mathrm{~mm}$ Hg. The four patients with pulmonary oedema had dilatations after successful diuretic treatment, and dilatation was performed in the patient with angina after a period of bed rest.

In each case the right femoral artery and right femoral vein were catheterised. A sheath was inserted into the right femoral vein, and a pacing wire was inserted into the right ventricle. This was done in case of arrhythmias at the time of dilatation. A specially developed $10 \mathrm{~F}$ sheath (Cooks) was inserted into the femoral artery. A pigtail catheter was passed to the ascending aorta and aortography performed to exclude major aortic incompetence. Routine Judkins coronary arteriography was performed to exclude significant left main stem disease in all cases. The aortic valve was then crossed with an 0.038 straight guide wire using an Amplatz left coronary catheter to facilitate positioning in the eccentric cusps. An exchange $J$ shaped guide wire and a pigtail catheter were advanced to the left ventricle for pressure recordings and angiography. The left femoral artery was cannulated to give simultaneous aortic and left ventricular pressures.

With the help of the exchange J guide wire Olbert or Medi-Tech balloon $C$ catheters were advanced and positioned across the aortic valve. Their $\widehat{\widehat{\Omega}}$ position was confirmed by $x$ ray screening (fig 2 ) and echocardiography (fig 3). Balloons varied in diameter from $8-16 \mathrm{~mm}$ in seven patients, but $]$ initially in the patient in case 3 only a $4 \mathrm{~mm}$ coronary angioplasty balloon $\mathbb{E}$ would negotiate the valve. Olbert balloons were inflated at 9 and 11 atmospheres for one minute up to $12 \mathrm{~mm}$, but above this size only Medi- 2 Tech balloons were available, and these were inflated to 4 atmospheres. Patients had two dilatations at each balloon size. Dilatations were continued until a target $50 \%$ reduction in aortic valve gradient had been achieved or until peroperative Doppler studies showed increasing aortic incompetence. Valves were dilated to $12 \mathrm{~mm}$ in all patients, to $14 \mathrm{~mm}$ in two, and to $16 \mathrm{~mm}$ in one.

After initial difficulties in stabilising the balloon in the valve cusps we inflated the balloon with it positioned two thirds of the way into the left ventricle. One operator inflated the balloon in stages, and the other manipulated it between the cusps with a rapid final inflation to lock it into

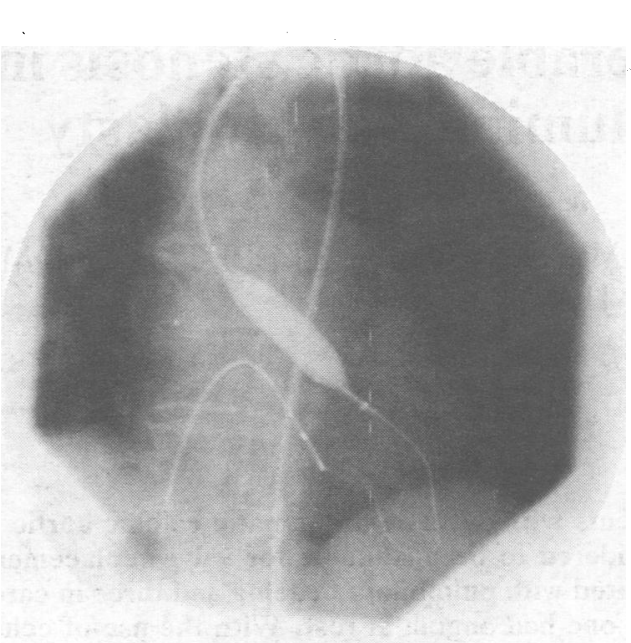

FIG 2-Balloon catheter inflated across calcified aortic valve. Guide wire used to stabilise and maintain position in the left ventricle, pacing wire in the right ventricle.

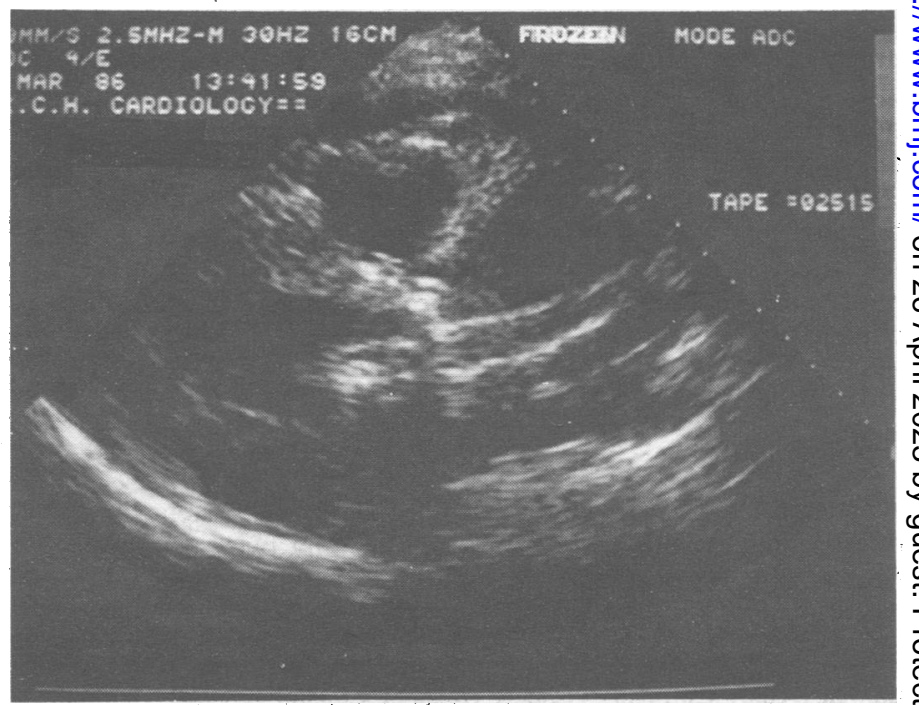

FIG 3-Peroperative echocardiography showing balloon inflated between aortic valve cusps.

position. All balloons were filled with contrast media for visualisation and safety. The Olbert balloons proved easier to use and manipulate as they allowed higher inflation pressures than the Medi-Tech balloons, which burst 
frequently when positioned in the aortic cusps. Heparin 5000 units was given for every 30 minutes of the procedure, which lasted from 45 minutes to three hours.

\section{Results}

\section{INTRAOPERATIVE AND POSTMORTEM STUDIES}

The 10 patients who underwent operative studies had tricuspid valves. The rigid nature of the orifice enabled the balloon to move freely through the valve, locking into position only when eccentrically placed between the commissures. All valves were calcified, rigid with fusion of the commissures. In none was the calcium considered friable. Dilatation was successful in seven patients, leading to increased leaflet mobility. In three patients no satisfactory position was found and the balloon would not lock into the cusps. When the balloon was inflated successfully the eccentric nature of the orifice prevented total occlusion to outflow. No embolisation occurred.

In the postmortem studies, which included one of a heart with a bicuspid valve (fig 1), inflation again led to cusp separation with no tearing of the ring or rupture, which might have led to embolisation.

\section{PATIENT STUDIES}

In all of the eight patients who underwent percutaneous transluminal aortic valvuloplasty a reduction in aortic valve gradient was achieved, with an average reduction of $40 \%$. One patient died four hours after the

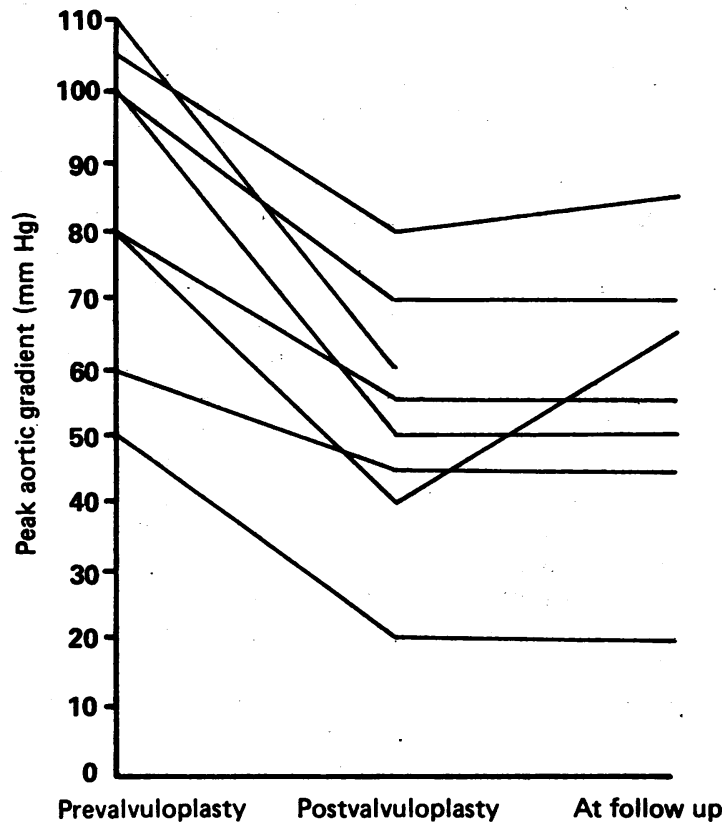

FIG 4-Peak aortic gradient before and immediately after valvuloplasty and at follow up (one to nine months).

procedure; the seven others remained well and improved symptomatically at up to nine months of follow up. Follow up studies by echocardiography and Doppler (Hewlett Packard) showed a consistent reduction in gradient (fig 4) with only a slight initial increase in aortic incompetence, which did not worsen.

The patient who presented with angina had a heavily calcified aortic valve and normal coronary arteries. Though dilatation reduced the gradient only from 105 to $80 \mathrm{~mm} \mathbf{H g}$, the symptoms improved, leading to minimal limitation nine months later. Three patients presented severely ill with pulmonary oedema and in shock. All needed intensive care before percutaneous transluminal aortic valvuloplasty. Two improved dramatically within 12 hours of the procedure, and inotropic support was stopped and diuretics reduced. One remained well nine months later, taking frusemide $40 \mathrm{mg}$ daily, and another remained well at three months, taking only a thiazide diuretic. (The first had normal coronary arteries and the second an occluded left anterior descending artery.) The patient who died was moribund on arrival, having failed to respond to conventional treatment, and because of severe lung disease and previous lung cancer she was not considered a suitable candidate for surgery. Balloon dilatation of her bicuspid valve was successful, but during a complex catheter exchange with the patient sitting up because of dyspnoea the guide wire perforated the left ventricle. The peroperative echo immediately identified the tamponade, which was aspirated. The patient made a good initial recovery but suffered a cardiac arrest four hours later with no recurrence of tamponade. All attempts at resuscitation failed.

Four patients presented with pulmonary oedema; all underwent successful dilatation and made excellent short and long term recoveries without incident.

No other serious complications occurred. Two patients experienced transient slowing of the heart rate and a fall in systematic pressure after inflations of $14 \mathrm{~mm}$ balloons but recovered quickly after the balloons were deflated. Two patients suffered bruising of the groin, which was managed with analgesia. All patients considered the procedure to be too long and complained of back pain and general discomfort, but all agreed to persevere with the help of analgesia.

Operator fatigue was an occasional problem, and the duration of exposures to $x$ rays was noted. Screening times varied from 10-50 minutes with an average of 35 minutes.

\section{Discussion}

We performed percutaneous transluminal aortic valvuloplasty in eight symptomatic patients with aortic stenosis who were considered to be unsuitable for aortic valve replacement. We did not attempt the procedure in patients of a similar age with a low risk at operation.

Our initial intraoperative and postmortem studies reassured us about the lack of embolisation and damage to the valve ring. We were sure that the rigidity of the valves and the eccentric nature of the cusps would prevent us from either damaging the valves by dislodging calcified material or totally occluding the orifice and causing syncope. Our findings are similar to those of McKay et al, and we also observed that the underlying pathological process may lead to subsequent restenosis. ${ }^{4}$ Interestingly, however, in our early follow up to nine months using serial echo-Doppler studies we did not identify major restenosis, though one patient showed a decrease in aortic incompetence, which may precede restenosis.

Our clinical results are encouraging. We performed percutaneous transluminal aortic valvuloplasty in three patients who presented with shock and pulmonary oedema, four with pulmonary oedema, and one with angina pectoris but normal coronary arteries. One of the patients in shock, who was gravely ill when the procedure was performed, died four hours later, partly because of technical complications (tamponade). Postmortem examination showed that the heavily calcified bicuspid aortic valve had been opened along the commissure. The results in the seven other patients were encouraging, with two patients surviving cardiogenic shock with the help of aortic valvuloplasty.

We believe aortic valvuloplasty has a role in the management of symptomatic patients with aortic stenosis who are considered to be poor candidates for surgery. In some it affords symptomatic benefit, and in others it may enable stabilisation of a poor haemodynamic state, allowing subsequent surgery with reduced operative risk. As with all new procedures, however, careful gathering of information is essential. We used peroperative echo and Doppler studies to identify the position of the balloon in the aortic cusps and to monitor developing aortic incompetence. In this way we stopped the procedure before a target $50 \%$ reduction in gradient was reached because of fears of a substantial increase in aortic incompetence. We believe peroperative Doppler monitoring is essential at this early stage in the procedure's development. As more cases are attempted problems will be encountered and it is imperative that they should be recorded for the benefit of all investigators. Fears of causing severe valvar damage or embolisation seem to be unfounded, but caution remains essential. Long term monitoring will identify problems with restenosis, but we did not encounter this in nine months of follow up. 
The use of balloon catheters has grown rapidly without scientific controls. ${ }^{5}$ Though we are convinced that percutaneous transluminal aortic valvuloplasty has a role in those considered to be unsuitable candidates for surgery, or perhaps those who do not wish to undergo surgery, we do not advocate its widespread use as an alternative to aortic valve replacement, which should be contemplated only as part of a controlled scientific study.

An aortic valvuloplasty registry is proposed; those who wish to participate should contact Dr Jackson.

\section{References}

1 Frank S, Johnston A, Ross J Jr. Natural history of valvular aortic stenosis. Br Heart I 1973;35:41-6. Jamieson WRE, Dooner J, Munro AL, et al. Cardiac valve replacement in the elderly: a review of 320 consecutive cases. Circulation 1981;64(suppl II):177-83.

3 Cribier A, Saoudi N, Berland J, Savin T, Rocha P, Letac B. Percutaneous transluminal valvuloplasty of acquired aortic stenosis in elderly patients: an alternative to valve replacement? vancet 1986; ; $63-7$.

4 McKay RG, Safian RD, Lock JE, et al. Balloon dilatation of calcific aortic stenosis in elderly patients: postmortem, intraoperative and percutaneous valvuloplasty studies. Circulation patients: postmort

5 Anonymous. The ubiquitous balloon [Editorial]. Lancet 1986;i:1129-30.

(Accepted 4 November 1986)

\title{
Unemployment and mortality: comparison of the 1971 and 1981 longitudinal study census samples
}

\author{
K A MOSER, P O GOLDBLATT, A J FOX, D R JONES
}

\begin{abstract}
Mortality in the period 1981-3 among men in the Office of Population Censuses and Surveys longitudinal study who were seeking work in 1981 was examined to investigate whether the finding of a high mortality rate among a comparable group of men who were followed up from the 1971 Census was repeated despite appreciable changes in the size and structure of the labour force over the intervening years. The pattern of mortality shortly after both censuses suggests that sick unemployed men were not categorised as seeking work, and it is concluded that for both samples the mortality of those who were reported to be seeking work was raised for reasons other than initial poor health. Other findings from the two censuses are also broadly similar. If confirmed after longer follow up this will add considerably to the evidence of the adverse health consequences of unemployment.
\end{abstract}

\section{Introduction}

The rise in unemployment since the mid-1960s, which accelerated in the early 1980s and shows little sign of diminishing, has led to much concern about the relation between unemployment and health. A principal concern of researchers is to disentangle the temporal associations between unemployment and a variety of measures of ill health. ${ }^{1}$ Two questions summarise much of the debate. Firstly, does unemployment cause a deterioration in health or, conversely, are the sick most likely to become unemployed? Secondly, does unemployment lead to poverty and other forms of disadvantage, which we know are associated with poor health, or are unemployment and poor health related because they are both associated with a previous low socioeconomic state, poorer education, and worse housing conditions?

Social Statistics Research Unit, City University, London EC1V 0HB

K A MOSER, MSC, research fellow

PO GOLDBLATT, MSC, PHD, senior research fellow

A J FOX, DIC, PHD, director

Department of Clinical Epidemiology and Social Medicine, St George's Hospital Medical School, London SW17 ORE

D R JONES, MSC, PHD, senior lecturer

Correspondence to: Ms Moser.
Changes in the level of unemployment are likely to have a direct effect on the findings of research into issues that are relevant to these questions. "When there is a lot going on almost everyone can find a job; when there is little, almost anyone can lose the job he has. It follows that those who are unemployed at a time of low unemployment are likely to have special problems, for whatever reasons; while in a period of high unemployment the unemployed will consist in increasing numbers of essentially 'ordinary' people down on their luck."'

We present the first analysis of mortality in the period 1981-3 of a group of men and women who were followed up prospectively from the 1981 Census, identifying in particular men who were unemployed in the week preceding the census and women who were married to unemployed men. Earlier analyses of deaths during 1971-81 from the Office of Population Censuses and Surveys longitudinal study showed that men who had been unemployed in 1971 had higher mortality rates than other men of the same age, even after accounting for factors such as social class, housing tenure, region of residence, and marital state..$^{3-5}$ Particularly high standardised mortality ratios were noted for suicide, lung cancer, and ischaemic heart disease. ${ }^{3}$ The mortality of the wives of unemployed men was also higher than that of other married women. This finding persisted when allowance was made for their own economic activity and housing tenure. ${ }^{34}$ These observations and the suggestion that the relative mortality of unemployed men rose as the duration of follow up increased were considered to support suggestions that raised mortality was a consequence, perhaps an indirect one, of unemployment.

Analysis of mortality in the longitudinal study after the 1981 Census can as yet be based only on data to the end of 1983 . Because of the increased levels of unemployment, however, larger numbers of deaths are available for analysis than in the comparable period of follow up after the 1971 Census. Our purpose was to see whether patterns of mortality that were observed for unemployed men and the wives of unemployed men who were identified in a period of high unemployment were similar to those observed in an earlier period of relatively low unemployment.

Kelvin and Jarrett suggested that more "ordinary" people are affected by unemployment in the 1980 s than was the case in the 1970s. If this is correct then the hypothesis that pre-existing ill health or deprivation produced higher mortality among the unemployed in the 1970s might lead to the expectation of a weaker association between unemployment and mortality in our more recent data. It might also be argued that a widening of the experience of unemployment across the community might reduce the stigma associated with being unemployed and even strengthen networks of support available to unemployed people and their 